\title{
LA INVESTIGACIÓN EN TORNO AL HUMOR VERBAL
}

\author{
JosÉ ANTONIO LLERA
}

Instituto de la Lengua Española

CSIC (Madrid)

\section{LA TEORÍA FRENTE A LA HIDRA HUMORÍSTICA}

Si la tragedia del humorista es que no se le suele tomar nunca en serio, la del teórico del humor no le va a la zaga. La visión que se tiene de su trabajo está sujeta a una paradoja que a menudo corre el riesgo de convertirse en complejo. A la vez que el humorista «de oficio» le reprocha ser demasiado abstruso, el especialista en cuestiones de humorismo cobra fama entre sus colegas de ocuparse de naderías difícilmente compatibles con un sueldo fijo o con una beca a cuenta del Estado. Es víctima de lo que me gusta llamar la maldición metonímica: el hecho de ocuparse de lo humorístico haría del crítico un ser también incongruente, con un discurso plagado de rupturas y ambigüedades. En suma, poco afín a la horma académica.

Y sin embargo, creo que el único punto de partida rentable para el investigador estriba en su convicción de que el humorismo es un asunto muy serio. Bien es cierto que esta seriedad — que no solemnidad- del objeto ha llevado no pocas veces a un callejón sin salida: aquel que se propone una definición cerrada de la noción de humor. Los ejemplos son abundantes: Kant (1792), Schopenhauer (1819), Bergson (1900), Freud (1905) o Pirandello (1908) ${ }^{1}$. Todos ellos presuponen que el humor tiene una esencia y tratan de revelar cuál es. Digo que esta postura lleva a aparejada su propia imposibilidad porque no podemos responder satisfactoriamente qué es el humor. La pregunta está mal enunciada. Desde mi punto de vista, la salida sólo puede atisbarse con una determinación del foco,

\footnotetext{
${ }^{1}$ Me he ocupado de forma extensa de estos autores en otro trabajo al que remito al lector interesado (Llera, 2003b). Cfr., asimismo, el artículo de Miguel Ángel Garrido Gallardo (1995) en el monográfico de la revista Ínsula dedicado al humor.
}

Rlit, LXVI, 132 (2004), 527-535 
trazando unas coordenadas, es decir, preguntándonos no qué es el humor, sino qué es qué humor. Una mínima perspectiva diacrónica pone de relieve que el humor es un concepto amplísimo, no sólo en el sentido de que sobrepasa lo literario, sino por el hecho de que se transforma y evoluciona con el tiempo. No puede capturarse sincrónicamente una imagen que es de por sí mutable y anamórfica. No presenta los mismos constituyentes la comedia de Aristófanes que el humor de las revistas satíricas de nuestra Restauración. Tiene poco que ver el humor de Óscar Wilde con el de Larra, del mismo modo que nos cuesta reconocer lazos entre Cervantes y el sombrío Quevedo. Si adoptamos una posición sincrónica vemos que el humor carece de ideología per se: puede apuntalar sistemas ideológicos conservadores o subversivos. Tampoco responde a una coloración afectiva que pueda fijarse a priori: puede atemperar los ánimos como observaron los tratadistas clásicos - Cicerón y Quintiliano-, pero también los exalta. Parafraseando a Jean Paul Sartre, cabría decir que la esencia del humor sólo resulta cognoscible si se indaga en su existencia. Sólo conociendo el contexto enunciativo o histórico, esto es, la variante pragmática en que opera una modalidad humorística determinada, podemos describir su semiótica. Hay tantas definiciones como humores: el número de especies que componen este conjunto es finito, pero variado y complejo.

En absoluto estoy proponiendo la renuncia al método, aunque han sido muchos los que han manifestado esta epojé. De nuevo la lógica de la metonimia: puesto que el humor es asunto complejo, con límites difusos, lo mejor será renunciar a toda tentativa de claridad de conceptual. El filósofo italiano Benedetto Croce pensaba que el humor, como cualquier estado psicológico, era indefinible. El ingenioso aforismo de Jardiel Poncela resume bien la tentación escéptica a la que me refiero: «Tratar de definir el humorismo es como pretender clavar por el ala una mariposa, utilizando de aguijón un poste del telégrafo» (1929: 93-94). El humor es una sustancia inaprensible, luego de nada servirían los instrumentos con que el erudito pretende diseccionarlo, ya que los excede. Nótese la paradoja: el humor fue en su origen un vocablo médico, desde Hipócrates de Cos (recordemos los cuatro humores corporales: el sanguíneo, el flemático, el atrabiliario y el melancólico); y, sin embargo, según esta hipótesis, se vuelve tan incorpóreo como el neuma. Lo cierto es que Jardiel sí trató de definir el humor literario, al menos el suyo, al igual que casi todos sus compañeros de generación. El problema de sus poéticas, como he señalado (Llera, 2001), es que por un lado adolecen de una gran vaguedad conceptual (ironía, sátira, parodia y humor resultan generalmente términos intercambiables) y por otro están presas de una historicidad a la que sus autores se muestran ciegos. Ramón Gómez de la Serna (1931) insiste en el factor crítico, incongruo y disolvente del humor, como buen vanguardista. $\mathrm{Si}$, por el contrario, leemos atentamente el discurso de recepción de Wenceslao 
Fernández Flórez (1945) en la Real Academia, corroboramos que está traspasado de idealismo. Su tesis recoge las ideas del romanticismo alemán (Richter, 1804), que ve el humor como una sublimación de la comicidad, donde sólo puede tener cabida la comprensión hacia el otro y la ternura. Ambos humoristas tienen razón y, al mismo tiempo, se equivocan: presentan un programa, una estética personal, pero no pueden, como pretenden, cerrar ontológicamente una categoría. Cierto: esbozan con buen pulso literario la genética de $s u$ humor creyendo que están diciendo qué es $e l$ humor. Otros ensayistas como Celestino Fernández de la Vega (1963) o Santiago Vilas (1968) se pierden por trochas equivocadas tratando de discriminar dos conceptos como los de comicidad y humor que históricamente no pueden separarse con claridad. Etimológicamente tampoco, ya que el salto de la acepción fisiológica a la literaria se da en el seno de la comedia de caracteres inglesa, en el siglo XVI. Objetan que en el humor es un producto de la Modernidad, pero confunden las palabras con las cosas.

La búsqueda de los rasgos distintivos del humor puede convertirse en una tarea existencial repleta de sentido. Todos los que hemos escrito sobre el humor en alguna ocasión hemos sentido también la necesidad de explicar qué significa para nosotros. Siempre he pensado que la médula del humor literario radica en la celebración melancólica de la provisionalidad del ser humano, de su azar. Pero entiendo que esta afirmación pertenece más bien al diario íntimo o al ensayismo literario y no a la investigación científica. La única forma de no dar lugar a malentendidos consiste en especificar el pacto con el lector, en aclarar en que género nos vamos a mover a la hora de escribir sobre el humor.

¿Cómo salir del atolladero? ¿Con qué espuelas mover a ese terco gorrino del humor que se nos ha parado en mitad de la cuesta? Desde mi punto de vista, se impone como medida cautelar delimitar cuál va a ser nuestra perspectiva, aunque reconozcamos que en el estudio del humor tenemos que estar siempre dispuestos a lo interdisciplinar. Insisto en que el humor es una noción muy vasta; podemos mirarlo con los anteojos de diversas materias: la Antropología (los estudios de Bajtin sobre el carnaval siguen siendo modélicos, al igual que Homo Ludens de Huizinga), la Psicología cognitiva, la Filosofía o la Lingüística, con una tradición venerable que pasa por Cicerón y Quintiliano, así como por el Gracián de la Agudeza y arte de ingenio (1648). El medio o canal es una coordenada más que aporta una serie de peculiaridades: hay humor en la literatura, en la prensa, en la música, en la pintura, en el cine... Por mi formación me he centrado más en enfoques retóricos y pragmáticos aplicados sobre todo a la literatura. Al contrario que algunos de mis colegas, que ven en la pragmática en general y en la teoría de la relevancia en particular una especie de panacea, reconozco que soy más ecléctico. Me interesa ver cómo funcionan los textos humorísticos, qué interacciones se producen, cómo los 
evalúan sus receptores. Pero considero que la pragmática no es la cumbre desde la cual se avista por completo el fenómeno. Creo más en una pragmática inscrita en la lingüística del texto y en la tradición que comprende a ambas, es decir, la antigua Retórica. Se trata, en efecto, de historizar también la pragmática y teorías afines como la de la relevancia, que ha cobrado un merecido prestigio en los últimos años desde que Sperber y Wilson publicaron su estudio en 1986.

La teoría de la relevancia ha explicado el humor como la incongruencia que se provoca por la incompatibilidad de dos supuestos contradictorios. El enunciado humorístico rompe un supuesto pertinente con el contexto. Para ejemplificar lo que digo sirve el chiste de Chumy Chúmez publicado en La Codorniz: "-Como es de la Sociedad Protectora de Animales, sólo maltrata personas» (3-IV-1960). Se frustran, en efecto, las expectativas del lector con una afirmación tan cínica, que desafía la lógica y la moral. Ahora bien, ya los tratadistas clásicos hablaban de la «decepta exspectatio» como fuente del humor; y los comediógrafos del Siglo de Oro no dejan de recurrir a esta estrategia para urdir el suspense y provocar la sorpresa. Los mismos perros con distintos collares, podríamos tal vez decirle al estudioso de la pragmática un tanto desmemoriado. Además: la ingente casuística del humor no puede reducirse a una expectación frustrada, a juegos con el principio de relevancia comunicativa.

La teoría de los marcos cognitivos o scripts, que desde 1985 en que Victor Raskin publica Semantic Mechanisms of Humor tuvo tan buena acogida entre la comunidad científica me temo que se ha convertido en una especie de doncella repudiada en los últimos años ante el avance de la pragmática y la lingüística del texto. Un modelo analítico posterior al de Raskin (lo que Attardo llama «Teoría General del Humor Verbal») tampoco parece haber resuelto la cuestión, ya que se plantea sólo como una semántica suplementada. Resulta eficaz si lo aplicamos a un tipo de texto generalmente narrativo como es el chiste. Ahora bien: ¿Qué hacemos entonces con discursos más extensos? ¿Cómo enfrentarnos al análisis de códigos no verbales como la pintura? ¿Qué hacemos con ese ornitorrinco del humor que es el chiste gráfico? Aunque parezca mentira, el repertorio de la elocutio retórica ha dado resultados más que convincentes cuando estamos ante esa clase de textos no verbales que llenan de perplejidad a eruditos como Raskin y Attardo. Basta recordar las lecturas que hace Roland Barthes (1978) de los cuadros de Arcimboldo, que se continúan en las taxonomías estructuralistas del Grupo $\mu$ (1992), sin olvidar los excelentes trabajos de Carrere y Saborit (2000) en España.

Mirar fijamente a la rueda del Humor puede hipnotizarnos primero y atropellarnos después. Tenemos que hacer un esfuerzo por mirar a cada uno de sus radios. El concurso simultáneo de la semántica y de la pragmática resulta capital. El humor literario no es un género, sino una modalidad que 
cruza transversalmente cualquier tipo de discurso, y que es aplicable a cualquier tema: el amor, la muerte, las relaciones interpersonales, las costumbres cotidianas, etc. Las intenciones del emisor a la hora de poner en práctica esta modalidad son diversas: elogiar, ridiculizar, divertir, manifestar algún tipo de adhesión... Tratemos, por ejemplo, de definir con brevedad, dos categorías como la sátira y el humor negro haciendo uso de la variante semántica y pragmática antes enunciada. La sátira sería una modalidad (género sólo en Roma) que se centraría en asuntos de actualidad con el objetivo de ridiculizarlos y de este modo alcanzar una suerte de corrección social. El humor negro, que puede yuxtaponerse a la sátira, se define como aquel que escenifica el dolor y la muerte tratando de provocar extrañamiento en el lector.

\section{UNA CODA HISTORIOGRÁFICA: ¿GENERACIONES PERDIDAS?}

Al abordar la cuestión historiográfica en el marco de lo contemporáneo, me pregunto: ¿cómo introducir en el canon algo tan heteróclito y bizarro como la literatura humorística? Porque ésa ha sido, creo, la miseria que generalmente ha tenido que asumir aquel que es encasillado como humorista: el margen como lugar de expiación. Por un lado, ha topado con una concepción integrista de lo literario, que desaloja casi siempre aquello que se publica en la prensa y no aparece recogido en libro. Afortunadamente, la teoría literaria no ha hecho más que repetir en los últimos años que no existen textos literarios en sí (lo que los formalistas rusos denominaron literaturnost), sino que es una comunidad de lectores la que en una época determinada reconoce como literarios un conjunto de textos. Y entre ellos cabe encontrar algunos que no merecieron esa consideración en épocas pasadas. Sólo desde este prejuicio se explica que revistas como Buen Humor (fundada en 1921 por el dibujante Sileno) y Gutiérrez (creada en 1927 por $\mathrm{K}$-Hito), que son esenciales para entender el fenómeno del humor vanguardista, aún no hayan merecido estudios en profundidad. La Codorniz, a la que he dedicado un libro (Llera, 2003a), tampoco ha corrido mucha mejor suerte dentro del ámbito de los estudios académicos. Sólo en fechas muy recientes, y de manera bastante tímida, escritores de la calidad de Julio Camba y Wenceslao Fernández Flórez parecen empezar a salir del purgatorio en el que estaban confinados, aunque todavía quedan perdidos en las hemerotecas, como pecios de su naufragio, centenares de artículos inéditos. En las simas del olvido yacen también nombres de humoristas estimables como Pérez de Zúñiga, Joaquín Belda, Noel Clarasó, Rafael Castellano o Fernando Perdiguero Camps. Ausentes sucesiones de difuntos.

¿Y qué decir de la llamada «otra generación del 27», la de Miguel Mihura, Jardiel Poncela, Tono, Edgar Neville y José López Rubio? Tuvo 
que ser Laín Entralgo el que llamase la atención sobre ellos inventando ese marbete que hizo una modesta fortuna cuando lo recogió López Rubio (1983) en su discurso de ingreso en la RAE. El adjetivo otra lo dice todo: es un grupo espurio frente al papel tutelar de los poetas. Se trata un rótulo que no me agrada: pone en evidencia una dialéctica interna, una lucha por un espacio cultural que los humoristas del 27 pocas veces reclamaron, quizá porque no acabaron de tener conciencia plena de grupo. Es obvio que el discurso de López Rubio era una especie de contraataque. Como muy bien ha señalado el profesor José-Carlos Mainer (1998), la historia de la literatura española del siglo $\mathrm{XX}$ ha sido muy aficionada al método generacional, que no es otra cosa que una hábil estrategia propagandística basada en la construcción de nóminas de autores cerradas a cal y canto. Lo fue el concepto de generación del 98, de cuño azoriniano, y lo fue la del 27, que, como es sabido, surge patrocinada por Gerardo Diego. Muchos prosistas estimables que cronológicamente pertenecen a la misma, como Benjamín Jarnés, sólo muy tardíamente han empezado a salir del olvido. Las múltiples fallas del método generacional son un hecho si pensamos que el rescate filológico de Ramón Gómez de la Serna se ha producido en los últimos veinte años. No han corrido desde luego la misma suerte sus discípulos, de quienes escasean los estudios críticos y cuyas obras se reeditan con dificultad. En cualquier caso, sería ingenuo pensar que es sólo el rígido canon generacional el que ha obrado en su contra. Median también factores ideológicos, ya que los humoristas del 27 aceptaron la dictadura franquista y trabajaron en sus medios de propaganda. Pero sería injusto decir que fue un grupo de adeptos al régimen. No sólo por el hecho de que algunos sufrieron censura - las novelas de Jardiel de antes de la guerra, por ejemplo, serán víctimas de la tijera nacional-católica cuando se reediten en la posguerra-, sino porque su individualismo bohemio y su formación vanguardista en la autonomía del arte les impidió llevar a cabo un proselitismo que no fuese impostado. El matiz me parece importante: aceptaron el régimen, pero no se consustanciaron con él. Nunca se sintieron vencedores, y quizás por eso estuvieron siempre más cerca de la melancolía y del desengaño que de la euforia. Sobre todo en el caso de Jardiel y de Mihura, sus dos componentes con más talento, puede decirse que fue una generación castrada: ambos se encontraron con un panorama teatral desolador, reacio a experimentos vanguardistas, dominado por el astracán, la comedia burguesa y el sainete. Por otra parte, el estado catatónico del cine español les impidió desarrollar plenamente sus dotes como guionistas (Ríos Carratalá, 2003), si bien no debe ocultarse que fue una generación víctima también de su tendencia a la dispersión artística.

Reconstruir un panorama posterior a los humoristas del 27 supone para el crítico certificar una orfandad. El caso del Álvaro de Laiglesia me parece muy elocuente, no sólo por su categoría de epígono de Jardiel Poncela, 
sino porque su novelística anticipa proféticamente nuestro presente. Frente a un Ramón en pugna con las palabras encerrado en el torreón de Velázquez y al Mihura que escribe a salto de mata, luchando con su pereza, Álvaro de Laiglesia va a sucumbir pronto a las exigencias del mercado editorial. A partir de los sesenta y hasta su muerte, su bibliografía crece al ritmo de una o dos novelas por año, que publica Planeta y, conocedor del bricolaje de este tipo de productos y de su público, pronto se convierte en un humorista de masas, aprovechando La Codorniz como plataforma publicitaria. En el panorama editorial de nuestros días ni siquiera encontramos esa especie de burocracia del humorismo en que degeneró la escritura de Álvaro de Laiglesia. Desaparecidas colecciones como las de Biblioteca Nueva, José Janés y Planeta, lo único que nos queda es el libro de encargo, muchas veces paupérrimo, la antología de urgencia y algunos francotiradores como José Luis Coll o Pgarcía. La ficción humorística, exangüe por las razones que he apuntado, ha sido reemplazada por el columnismo de humor, y es muy probable que el lector haya salido ganando en esta metamorfosis si se acerca a los artículos de Francisco Umbral, Elvira Lindo, Antonio Burgos, Eduardo Mendicutti o Jaime Campmany, entre otros.

¿Vivimos acaso inmersos en una cultura que reprime lo humorístico? La respuesta depende de nuevo del tipo de humor en que estemos pensando. En la cultura posmoderna de la imagen, el simulacro y el kitsch, abundan los shows televisivos, se multiplican las series con risas enlatadas y crecen los pastiches. Salvo excepciones, es un humor con escasa mordiente, que barniza suavemente el discurso, neutralizando cualquier intento de construir un núcleo estable de valores (Lipovetsky, 1983). Queremos reír sin sentirnos culpables ni comprometidos. Encontrar las fisuras de este humor light pasa por un planteamiento seguramente utópico, es decir, un humor ético que haga frente al imperio de la razón cínica y de la voluntad de poder. Claro que este compromiso no es distinto del que emplaza al discurso filosófico «serio».

\section{REFERENCIAS BIBLIOGRÁFICAS}

AtTARdo, S. (1994), Linguistic Theories of Humor, Berlín-Nueva York, Mouton de Gruyter.

BAJTIN, M. M. (1965), La cultura popular en la Edad Media y Renacimiento, trad. de J. Forcat y C. Conroy, Barcelona, Seix Barral, 1974.

BARTHES, R. (1978), «Arcimboldo o El retórico y el mago», en Lo obvio y lo obtuso. Imágenes, gestos, voces, Barcelona, Paidós, 1986, pp. 133-151.

Bergson, H. (1900), La risa, trad. de M. ${ }^{a}$ Luisa Pérez Torres, Madrid, Espasa-Calpe, 1986 ( $2 .^{\mathrm{a}}$ ed.).

CARrere, A. y SABOrit, J. (2000), Retórica de la pintura, Madrid, Cátedra.

CiCERón, M. T., De oratore, ed. bilingüe latín-inglés de E. W. Sutton y H. Rackham, Cambridge, Heinemann y Harvard University Press, 1967. 
FERBÁNDEZ DE LA VeGA, C. (1963), El secreto del humor, Buenos Aires, Nova, 1967. FERBÁNDEZ FLÓREZ, W. (1945), El humor en la literatura española [Discurso de recepción en la RAE], en Obras selectas, Barcelona, Caro Raggio, 1979, pp. 21-49.

FREUD, S. (1905), El chiste y su relación con lo inconsciente, trad. de Luis LópezBallesteros, Madrid, Alianza, 1969.

GARRIDO Gallardo, M. Á. (1995), «Jalones para una teoría del humor», Ínsula, núm. 579, marzo, pp. 1-4.

GómEZ DE LA SERNA, R. (1931), «Humorismo», en Ismos, Madrid, Guadarrama, 1975, pp. 197-233.

Gracián, B. (1648), Agudeza y arte de ingenio, ed. de E. Correa Calderón, Madrid, Castalia, 1969, 2 vols.

GRUPO $\mu$ (1992), Tratado del signo visual, trad. de Manuel Talens, Madrid, Cátedra, 1993.

HuizingA, J. (1938), Homo ludens, trad. de Eugenio Imaz, Madrid, Alianza, 1972.

JARDIEl PONCElA, E. (1929), Amor se escribe sin hache, ed. de Roberto Pérez, Madrid, Cátedra, 1999.

KanT, E. (1790), Crítica del juicio, trad. de M. García Morente, Madrid, Espasa-Calpe, 1977.

Laín Entralgo, P. (1972), «El futurismo irónico de Jardiel», La Gaceta Ilustrada, 28 de mayo, p. 15.

LiPOVETSKY, G. (1983), La era del vacío, trad. de Joan Vinyoli y Michèle Pendanx, Barcelona, Anagrama, 1986.

LÓPEZ RUBIO, J. (1983), La otra Generación del 27 [Discurso de recepción en la RAE], Madrid, Real Academia Española.

LleRA, J. A. (2001), «Poéticas del humor: desde el novecentismo hasta la época contemporánea», Revista de Literatura, t. LXIII, núm. 126, pp. 461-476.

- (2003a), El humor verbal y visual de La Codorniz, Madrid, CSIC.

- (2003b), «Una aproximación interdisciplinar al concepto de humor», Signa, núm. 12, pp. 613-628.

MAINER, J.-C. (1998), «Sobre el canon de la literatura española del siglo XX», en Sullà, E. (comp.) (1998), El canon literario, Madrid, Arco/Libros, pp. 271-299.

PIRANDELlO, L. (1908), L'umorismo: saggio, Firenze, Luigi Battistelli, 1920.

RASKIN, V. (1985), Semantic Mechanisms of Humor, Dordrecht-Boston-Lancaster-Tokyo, D. Reidel Publishing Company.

RichTeR, J. P. (1804), Introducción a la Estética, ed. de Predo Aullón de Haro, trad. de Julián de Vargas, Madrid, Verbum, 1990.

Ríos Carratala, J. A. (2003), Dramaturgos en el cine español (1939-1975), Alicante, Universidad de Alicante.

SCHOPENHAUER, A. (1819), «Teoría de la risa», en El mundo como voluntad y representación, I, trad. de Eduardo Ovejero y Maury, Madrid, Aguilar, 1928, pp. 168-175.

SPERBER, D. y WiLSON, D. (1986), La relevancia, trad. de Eleanor Leonetti, Madrid, Visor, 1994.

TORRES SÁNCHEZ, M. a Á. (1999), Estudio pragmático del humor verbal, Cádiz, Universidad de Cádiz.

VILAS, S. (1968), El humor y la novela española contemporánea, Madrid, Guadarrama.

YUS RAMOS, F. (1997), La interpretación y la imagen de masas: un modelo pragmático aplicado al discurso del cómic inglés, Alicante, Instituto de Cultura Juan Gil-Albert. 


\title{
RESUMEN
}

\section{La investigación en torno al humor verbal, por José Antonio Llera.}

El autor de este artículo propone un acercamiento diacrónico a la modalidad humorística, y critica cualquier aproximación de carácter esencialista que trate de fijar el concepto como una categoría cerrada. Cada una de las especies del espectro humorístico - la sátira y la ironía, por ejemplo- debieran abordarse desde una óptica que combine la semántica con la pragmática, sin olvidar el concurso de la antigua retórica. En cuanto a la historia más reciente del humorismo hispano, se valoran los autores más representativos de la llamada «otra generación del 27», reflexionando sobre la causa de su postergación y sobre la ausencia en la actualidad de un relevo de verdadera calidad literaria.

Palabras Clave: Humor, pragmática, retórica, «otra generación del 27».

\begin{abstract}
The author of this article suggests a diachronic approach to the humorous mode and criticizes any essentialist theory that defines the concept as a closed category. Every kind of humour within the whole spectrum, i.e. satire and irony, should be looked at following semantic and pragmatic principles, not forgetting the influence of classical rhetoric. As regards the recent history of Spanish humour, the contributions of the most important authors of the so-called «otra generación del 27» shall be analyzed by considering the reasons for their ostracism and for the lack of a present high quality generation of authors able to take over their literary tradition.
\end{abstract}

Key Words: Humour, Pragmatics, Rhetorics, (so called) «otra generación del 27». 